\title{
Characterization of protein expression of Platanus pollen following exposure to gaseous pollutants and vehicle exhaust particles
}

\author{
Senlin Lu • Jingjin Ren $\cdot$ Xiaojie Hao $\cdot$ Dingyu Liu $\cdot$ Rongci Zhang \\ Minghong Wu $\cdot$ Fei Yi $\cdot$ Jun Lin $\cdot$ Yonemochi Shinich $\cdot$ Qingyue Wang
}

Received: 8 April 2013/Accepted: 24 January 2014/Published online: 8 February 2014

(C) The Author(s) 2014. This article is published with open access at Springerlink.com

\begin{abstract}
Being major ornamental street trees, species of Platanus are widely planted in the Shanghai urban area. A great deal of allergenic Platanus pollen is released from the trees and suspended in the atmosphere during its flowering season, ultimately causing allergic respiratory diseases. Few papers have focused on the distribution of this type of pollen and its expression of allergenic proteins. In order to investigate any differences in protein expression in Platanus pollen following exposure to gaseous and particulate pollutants, a special apparatus was designed. Exposure condition (such as temperature, humidity, and exposure time) of Platanus pollen and gaseous pollutants can be simulated using of this apparatus. Fresh Platanus orientalis pollen, pollutant gases $\left(\mathrm{NO}_{2}\right.$,
\end{abstract}

S. Lu (凹) - J. Ren · X. Hao · D. Liu · R. Zhang ·

M. Wu $\cdot$ F. Yi

School of Environmental and Chemical Engineering,

Shanghai University, Shanghai 200444, China

e-mail: senlinlv@staff.edu.cn

\section{J. Lin}

Shanghai Institute of Applied Physics, Chinese Academy of Sciences, Shanghai 201800, China

\section{Y. Shinich}

Center for Environmental Science in Saitama, Saitama 374-0115, Japan

Q. Wang

School of Science and Engineering, Saitama University, Saitama 338-8570, Japan
$\mathrm{SO}_{2}, \mathrm{NH}_{3}$ ), and typical urban ambient particles (vehicle exhaust particles, VEPs) were mixed in this device to examine possible changes that might occur in ambient airborne urban pollen following exposure to such pollutants. Our results showed that the fresh $P$. orientalis pollen became swollen, and new kinds of particles could be found on the surface of the pollen grains after exposure to the pollutants. The results of SDS-PAGE showed that five protein bands with molecular weights of $17-19,34,61,82$, and $144 \mathrm{kDa}$, respectively, were detected and gray scale of these brands increased after the pollen exposure to gaseous pollutants. The two-dimensional gel electrophoresis analysis demonstrated that a Platanus pollen allergenic protein (Pla a1, with a molecular weight of $18 \mathrm{kDa}$ ) increased in abundance following exposure to pollutant gases and VEPs, implying that air pollutants may exacerbate the allergenicity of pollen.

Keywords Platanus pollen - Air pollution · Protein expression

\section{Introduction}

Global warming has been cited as the cause of the increase in abundance of atmospheric pollen that has been observed over the last three decades (D'Amato et al. 2010), additionally, meteorological changes (such as, temperature, extreme weather events) 
induced by global warming have impacted the production, distribution, dispersion, and allergenic content of aeroallergens and the growth and the distribution of organisms that produce them (i.e., weeds, grasses, trees, and fungus) (Reid and Gamble 2009). Further, as the rapid growth of urban green areas continues, along with the number of plant species used, a corresponding increase in the rate of pollen allergies among patients has been reported (Riediker et al. 2001). Several studies have shown that the increasing incidence of pollen allergies has become a global problem (Ishizaki et al. 1978; Hwang et al. 2005; Bosch-Cano et al. 2011); for example, pollinosis has increasingly been found to have a profoundly negative effect on human health in Japan (Wang et al. 2011), in Europe (Fernandez-Gonzalez et al. 2010; Bosch-Cano et al. 2011), and in north America (Ziska et al. 2011). In China, the average incidence rate of hay fever is about $0.5-1 \%$; however, in particular areas, this figure can reach up to $5 \%$, such as in Wuhan, which is located in the center of China (Shi and Zhu 2009). The results of a survey conducted by our group also found that asthma caused by ambient pollen has led to $8.23 \%$ of Shanghai children not being able to participate in outdoor physical activities and caused $5.02 \%$ to be absent from educational services for more than two months (unpublished report). However, ambient particulate matter pollution remains at high levels in Shanghai (Lu et al. 2011). Our previous study demonstrated that the amount of ambient pollen and the atmospheric concentration of fine/ultrafine particulates is both important with respect to human health (Feng et al. 2011; Lu et al. 2011) and that pollen grains were one of the components in Shanghai atmospheric fine particulates (Lu et al. 2008). Furthermore, there were more fine particles observed on the surface of the allergenic pollen collected in urban areas compared with those collected in the suburban areas (Feng et al. 2011). Considering the fact that ambient pollen can be a carrier of various pollutants (atmospheric fine particulates, $\mathrm{SO}_{\mathrm{x}}, \mathrm{NO}_{\mathrm{x}}$, etc.) (Okuyama et al. 2007; Bellanger et al. 2012) and that species of Platanus are widely planted in parks and avenues in Shanghai, we hypothesized that Platanus pollen and air pollutants may have synergistic effects with regards to allergenicity and human health.

Several researchers have focused on the synergetic effects that may result from the interaction between air pollutants and pollen allergens. Parnia et al. (2002) suggested that traffic pollution generated ozone, nitrogen oxides $\left(\mathrm{NO}_{\mathrm{x}}\right)$, and inhalable particulate matter $\left(\mathrm{PM}_{10}\right)$, and these were likely the atmospheric pollutants responsible for promoting hay fever. Okuyama et al. (2007) reported that airborne fine particulates were easily absorbed by pollen, and this interaction had a negative impact on human health. In addition, the pollen's migration and precipitation into the nasal cavity and other parts of the respiratory tract, and it was argued that heavy metals and acidic substances contained in polluted pollen grains may exacerbate the occurrence of hay fever in urban residents. Chehregani and Kouhkan (2008) demonstrated that diesel vehicle emissions particles (DEPs) were capable of inducing pollen to produce new allergenic proteins.

Based on the literature cited above, we hypothesized Platanus pollen and air pollutants have synergistic effects. In order to testify our hypothesis, an exposure apparatus was designed to simulate the interaction between pollen and typical air pollutants. Our primary aim is to elucidate how environmental conditions likely contribute to the expression of allergenic proteins released by Platanus pollen.

\section{Materials and methods}

\subsection{Platanus pollens sampling}

Fresh Platanus pollen grains were sampled from Platanus orientalis tree trimmers (these trees located in the campus of East China Normal University). After branches with inflorescences were cut off the tree, the inflorescences were air-dried at room temperature and kept from any pollutants off. Pollen grains were collected from the dried inflorescences. The collected pollen was kept at $-4{ }^{\circ} \mathrm{C}$ until subsequent use.

\subsection{Pollutants exposure apparatus}

In order to investigate allergenic protein changes in Platanus pollen induced by air pollutants, an apparatus was designed to simulate the exposure of pollen to ambient urban gaseous air pollutants, including $\mathrm{SO}_{2}$, $\mathrm{NO}_{2}$, and $\mathrm{NH}_{3}$ (Shanghai Weichuang Standard Gas Analytical Co. Ltd.) as well as vehicle exhaust particles (VEPs, NIES, National Institute for Environmental Studies, Yatabe-Machi, Tsukuba, Japan). The exposure 


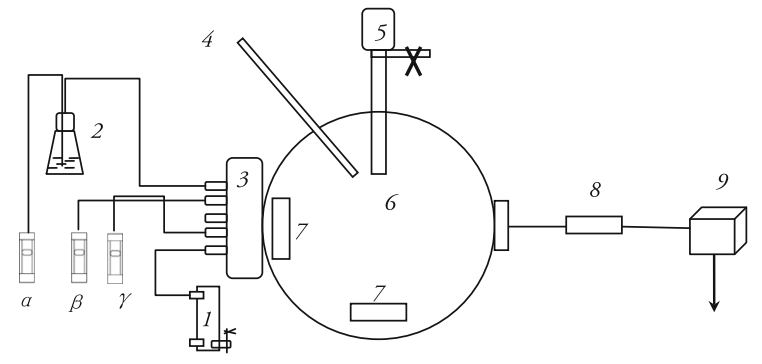

Fig. 1 Diagram of the apparatus designed to simulate pollen exposure to air pollutants. $\mathrm{SO}_{2}, \mathrm{NO}_{2}$, and $\mathrm{NH}_{3}$ were transferred into the reactor, and the pollen was suspended in the reactor; after a set amount of time, pollen grains were collected according to the protocol. The apparatus contained the following components: 1-clean air; 2-gas-washing bottle; 3-mixer for gases; 4-sensor for temperature and humidity; 5-pollen; 6-chamber; 7-electronic fan; 8-sampler inlet head with filter; and 9-pump, $\alpha-\mathrm{SO}_{2}, \beta-\mathrm{NO}_{2}, \gamma-\mathrm{NH}_{3}$

devices included an airflow meter, a humidification device, a mixer for gases, a temperature and humidity sensor, a pollen container, an exposure chamber, an electronic fan, a sampler inlet head with filter, and a low capacity pump (Fig. 1). The exposure chamber is the where the reaction between Platanus pollen and atmospheric pollutants $\left(\mathrm{SO}_{2}, \mathrm{NO}_{2}, \mathrm{NH}_{3}\right)$ took place. The particle capture device was used to capture the exposure pollens with a polycarbonate membrane filter.

Pollen grains were suspended by electronic fans in the chamber after $\mathrm{SO}_{2}(0.1 \mathrm{~L} / \mathrm{min}), \mathrm{NO}_{2}(0.54 \mathrm{~L} / \mathrm{min})$, $\mathrm{NH}_{3}(0.03 \mathrm{~L} / \mathrm{min})$ were transferred into the chamber. The mole ratio of $\mathrm{SO}_{2}, \mathrm{NO}_{2}$, and $\mathrm{NH}_{3}$ was kept 30:200:30 in the chamber (Yamamoto et al. 1995; Wang, unpublished report 2012), the mass concentration of the gaseous pollutants was 5-6 times higher compared with their measured mass levels in the air (Shanghai Environmental Bulletin claimed that mass levels of $\mathrm{SO}_{2}$ and $\mathrm{NO}_{2}$ were 23 and $46 \mu \mathrm{g} / \mathrm{m}^{3}$, respectively (SEPB 2012), while the humidity and temperature in the inner environment of the chamber were kept at $60 \%$ and $25{ }^{\circ} \mathrm{C}$, respectively (which are similar to the values seen during pollen season).

\subsection{Scanning electron microscopy (SEM) analysis}

A very small amount of pollen was put on a doublesided adhesive and conductive carbon tape with a clean wooden pick. Following this step, gentle blowing was applied so as to remove loosely stuck pollens from the carbon tape. The remaining pollen was examined by SEM.

After the carbon tape was coated with gold, the sample was observed under a scanning electron microscope (Zesis ultra 55 FE-SEM; Germany) with the following parameters: voltage, $30 \mathrm{kV}$; resolution, $3 \mathrm{~nm}$; and scanning distance, $15.0 \mathrm{~mm}$. The chemical composition on the pollen was investigated by X-ray energy dispersive spectroscopy (EDX) (UK 7421, Oxford).The EDX spectrometer was Link ISIS spectrometer with a $\mathrm{Si}(\mathrm{Li})$ detector, which allows X-ray detection from elements higher than carbonate $(Z>6)$ (Lu et al. 2006).

\subsection{Protein analysis}

Sodium dodecyl sulfate polyacrylamide gel electrophoresis (SDS-PAGE) was used for protein analysis. A modified version of the pollen protein extraction protocol described by Varela et al. (1997) was used in this study. Briefly, $2 \mathrm{~g}$ of fresh Platanus pollen was defatted with acetone $(3.44 \mathrm{~mol} / \mathrm{L})$, dried, and extracted in $40 \mathrm{ml}$ of $0.01 \mathrm{M}$ phosphate and $0.15 \mathrm{M}$ $\mathrm{NaCl}$ phosphate-buffered saline (PBS; $\mathrm{pH}=8$ ); the mixture $(1: 20 \mathrm{wt} / \mathrm{vol})$ was stirred for $12 \mathrm{~h}$ at $4{ }^{\circ} \mathrm{C}$. The suspension was filtered through a cellulose filter paper (Whatman Ltd., Maidstone, UK), dialyzed against PBS, and sterilized by $0.22 \mu \mathrm{m}$ filtration. The total protein content of the pollen extracts was determined by the Bradford protein assay using bovine serum albumin (BSA) as the standard. Extracted proteins were separated by $10 \%$ SDS-polyacrylamide gel electrophoresis ( $90 \mu \mathrm{l}$ of each pollen extract per well) and visualized by Coomassie blue staining.

\subsection{Analysis of protein expression by two- dimensional gel electrophoresis (2-DE)}

The two-dimensional gel electrophoresis (2-DE) protocol was as described by Sheoran et al. (2009). An equal amount of protein $(200 \mu \mathrm{g})$ sample was mixed with fresh rehydration buffer (9 M Urea, $4 \%$ CHAPS, $1 \%$ DTT, $1 \%$ IPG buffer, and trace amounts of bromophenol blue) to a total volume of $450 \mu \mathrm{L}$. The protein samples were then added to the strip holder. The isoelectric focusing protocol was carried out at $20{ }^{\circ} \mathrm{C}$, with $50 \mu \mathrm{A}$ per strip. The strips were laid across the top of the gel, making sure that the gels were lying flush with one another. After the sealing solution 
cooled and solidified, the strip was moved to the electrophoresis apparatus (Ettan-DALT-Six system; GE healthcare; USA). Electrophoresis was carried out at $15{ }^{\circ} \mathrm{C}$, and the gel was run at $100 \mathrm{~V}$ for $45 \mathrm{~min}$, followed by $200 \mathrm{~V}$ for $6-8 \mathrm{~h}$ (until the bromophenol blue band reached the bottom of gel). The gel was visualized by silver staining as described previously (Shevchenko et al. 1996). All gel images were processed by a three step procedure: (1) protein spot detection; (2) quantify volume of the selected spot; and (3) match grayscale values using Bio-Rad PDQuest 8.0 software.

\subsection{Platanus protein identification with mass spectrometry (MS)}

Platanus protein identification by mass spectrometry (MS) was carried out using the protocol described by Sheoran et al. (2009). Briefly, excised protein spots were automatically destained, dehydrated, reduced with DTT, alkylated with iodoacetamide, and digested with trypsin with a MassPREP protein digest station (Wates/Micromass; Manchester, UK). Samples were suspended in $5 \mu \mathrm{L} 0.1 \%$ TFA, followed by mixing (in 1:1 ratio) with a matrix consisting of a saturated solution of $\alpha$-cyano-4-hydroxy-trans-cinnamic acid in $50 \% \mathrm{ACN}$ and $0.1 \%$ TFA. The $1 \mu \mathrm{L}$ mixture was spotted on a stainless steel sample target plate. Peptide MS and MS/MS were performed on an MALDI-TOF/ TOF (AB SCIEX; USA) plus mass spectrometer. Data were acquired in a positive MS reflector using a CalMix 5 standard to calibrate the instrument. Both the MS and MS/MS data were integrated and processed with the use of the GPS Explorer v3.6 software with default parameters. Employing the combined MS and MS/MS spectra, proteins were successfully identified based on $95 \%$ or higher confidence interval of their scores in the MASCOT v2.1 search engine (Matrix Science Ltd.; London, UK).

\section{Results}

3.1 Microscopic characterization of ambient pollen

Results of SEM analysis revealed that the $P$. orientalis pollen grains were suboblate, with a diameter
20-30 $\mu \mathrm{m}$, and with trenches on its surface. The surface of fresh pollen grains became swollen after exposure to the mixture of gases. Further, EDX spectral analysis demonstrated that $\mathrm{C}, \mathrm{N}$, and $\mathrm{O}$ were the main elements on the surface of pollen before exposure to the air pollutants (Fig 2a). After $1 \mathrm{~h}$ exposure, new particles could be found on the surface (Fig 2b), and these were composed of $\mathrm{K}, \mathrm{O}, \mathrm{N}$, and $\mathrm{C}$. The number of the new particles increased with exposure time, and $\mathrm{S}$ could be detected in the new particles formed after $8 \mathrm{~h}$ exposure (Fig 2c). The formation of these new particles suggested that a chemical reaction occurred during the contact of the pollen with the gases.

\subsection{Separation of total protein by SDS-PAGE}

The results of SDS-PAGE analysis showed that protein bands with molecular weights of 17-19, 34, 61,82 , and $144 \mathrm{kDa}$ could be found in samples of fresh pure Platanus pollen (herein thereafter named as APB). After pollen exposure to gaseous pollutants for 1 , and $8 \mathrm{~h}$, the main protein bands became dark, suggesting more protein was expressed by the pollen grains. In this study, a new protein band was found after the exposure of pollen to gaseous pollutants and VEPs for $8 \mathrm{~h}$. The presence of the new protein band, with an approximate molecular weight of $26.5 \mathrm{kDa}$, implies that VEPs stimulate fresh Platanus pollen to express new proteins.

\subsection{Differences in protein expression identified by two-dimensional gel electrophoresis (2- DE)}

The 2-DE assay has been widely used to distinguish differences between complex protein extracts. On the basis of a range of biochemical properties, including charge (pI), size (M), and hydrophobicity, proteins can separated from one another with this technique. Figure 4 depicts the protein spots showing changes after the exposure of $P$. orientalis pollen to air pollutants. Grayscale values (listed in Table 1) of 14 protein spots, p103, p119, p1005, p1007, p1101, p1110, p1211, p2002, p3001, p3306, p4214, p5301, p6107, and p8000, were found to increase following different exposure conditions. It was worth to note that grayscale value of p1007 increased more than 4 

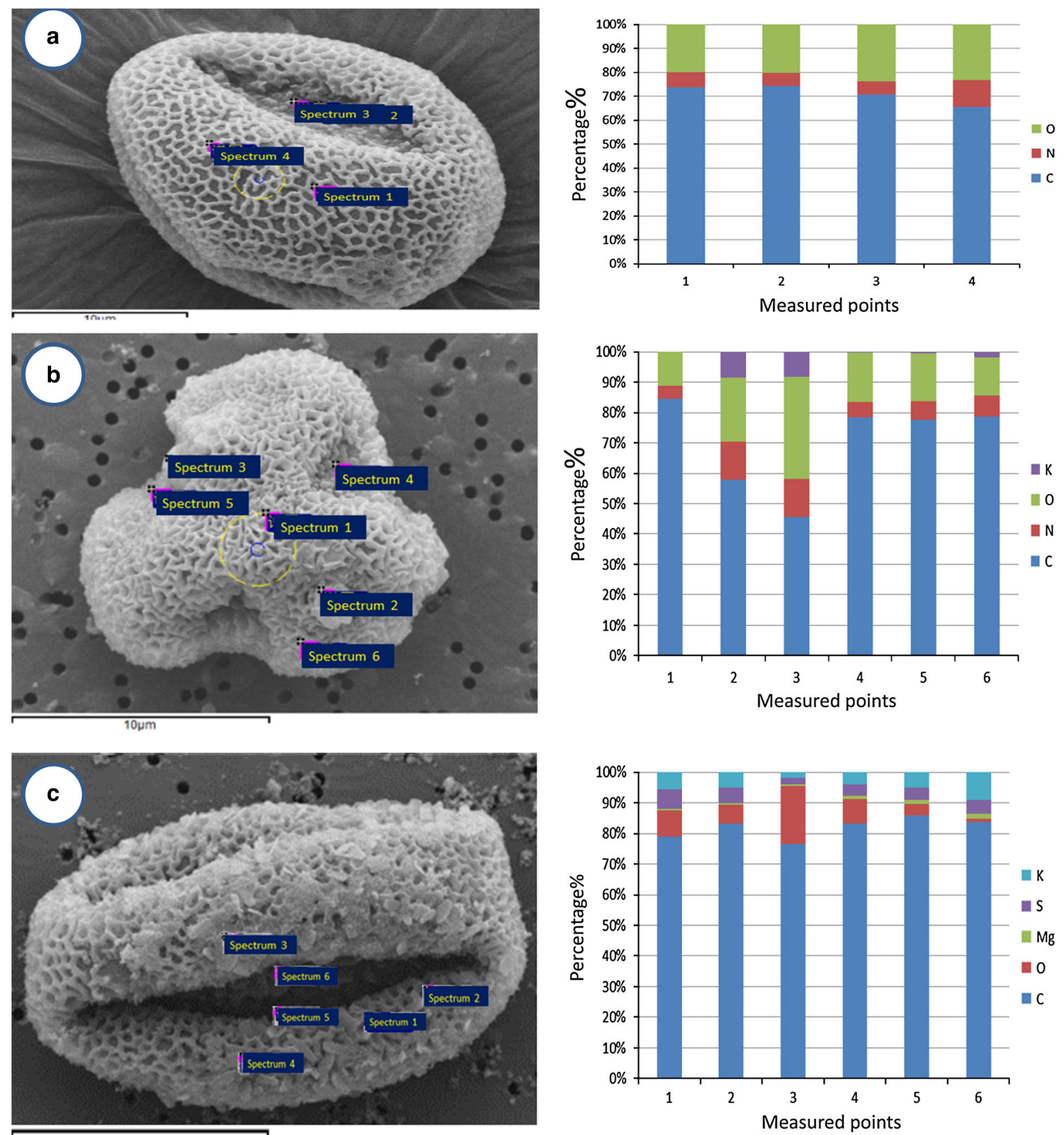

Fig. 2 Microscopic images of the Platanus orientalis pollen before and after exposure to air pollutants. a Fresh pollen before exposure; b pollen after $1 \mathrm{~h}$ exposure; c pollen after $8 \mathrm{~h}$ exposure. The corresponding EDS analysis of every time point is displayed on the left

times after the pollen exposure to gaseous pollutants and VEPs for $8 \mathrm{~h}$. The protein spot (p8000) with molecular weight $\sim 18 \mathrm{kDa}$ and $\mathrm{pI} \sim 9.3$ was identified as Pla a1 according to the literature (Asturias et al. 2002).

\subsection{MS analysis}

Two protein spots (p1007 and p8000) in the 2-DE gel were selected to identify their protein constitution using of mass spectrometry (Fig. 5). 


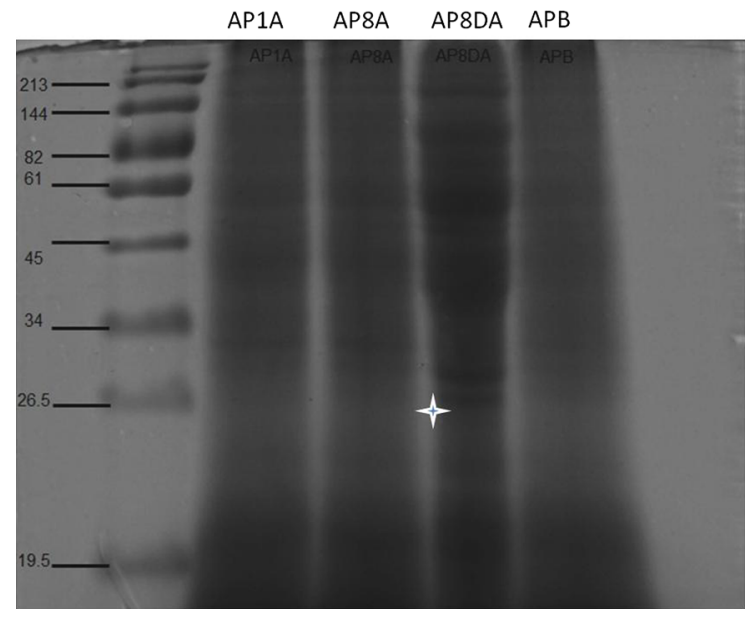

Fig. 3 Protein profile of Platanus pollen extracts. Major protein bands were detected, and a new band $(26.5 \mathrm{kDa})$ was found in AP8DA (indicated by star). AP1A and AP8A refer to pollen exposed to pollutant gases for one and $8 \mathrm{~h}$, respectively. AP8DA refers to pollen exposed to pollutant gases and VEPs for $8 \mathrm{~h}$. APB refers to pollen before exposure to pollutants
According to Mascot Score Histogram, four proteins were found in spot p1007 (Table 2): gil12229949 (RecName: Full=40S ribosomal protein S12); gil195604208 (40S ribosomal protein S12 [Zea mays]); gil226505142 (ribosomal protein, S12 (homolog) [Zea mays]); and gil116782336 (unknown [Picea sitchensis]). None of these proteins are a documented allergenic protein. Only one protein was found in protein spot p8000: gil29839547 (RecName: Full=Putative invertase inhibitor; AltName: Full=Pollen allergen Pla a 1; AltName: Allergen=Pla a 1; Flags: Precursor). The amino acid sequence of the Pla a 1 is: MKLSFSLCIF FFNLLLLLQA VISADIVQGT CKKVAQRSPN VNYDFCVKSL GADPKSHTAD LQ GLGVISAN LAIQHGSKIQ TFIGRILKSK VDPALKKYLN 101DCVGLYADAK SSVQEAIADF KSKDYA SANV KMSAALDDSV TCEDGFKEKK GIVSPVTKEN KDYVQLTAIS LAITKLLGA. This amino acid sequence further demonstrated the identity of the allergenic protein expressed by the Platanus pollen.
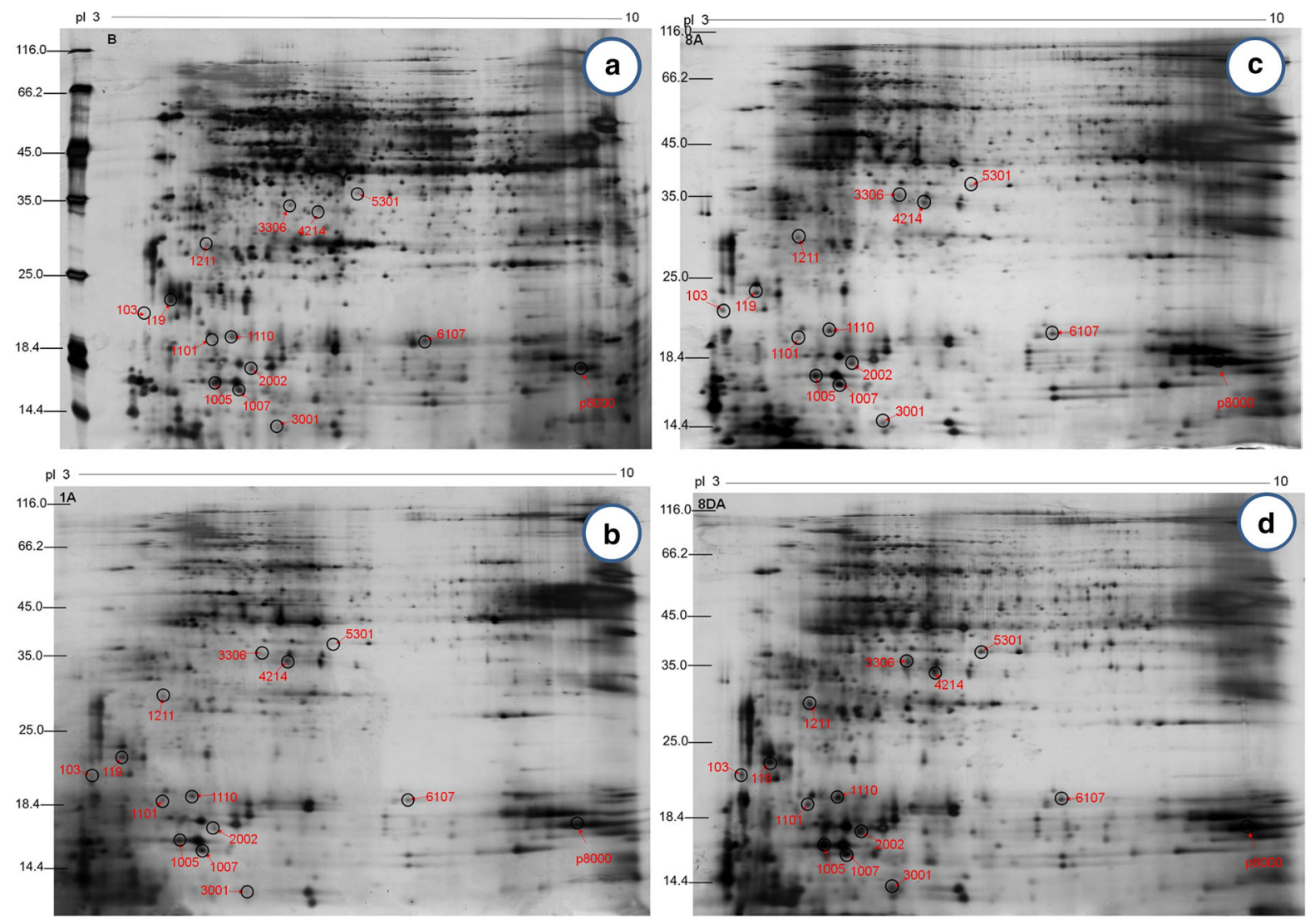

Fig. 4 Two-dimensional gels of Platanus pollen protein extracts. Molecular masses are given in kDa, and the approximate isoelectric points are shown. a APB; b AP1A; c AP8A; and d AP8DA 
Table 1 Variation in the grayscale values of protein spots

\begin{tabular}{lrrrr}
\hline Spot no. & \multicolumn{1}{l}{ APB } & \multicolumn{1}{l}{ AP1A } & \multicolumn{1}{l}{ AP8A } & \multicolumn{1}{c}{ AP8DA } \\
\hline p103 & 20.84 & 479.03 & $3,149.84$ & $3,701.75$ \\
p119 & $1,524.36$ & $1,911.98$ & $2,784.16$ & $3,222.32$ \\
p1005 & $9,339.34$ & $11,145.98$ & $16,187.35$ & $17,450.83$ \\
p1007 & $2,848.85$ & $4,783.29$ & $10,353.78$ & $12,698.74$ \\
p1101 & 20.13 & 371.25 & $2,147.11$ & $2,181.65$ \\
p1110 & $2,156.73$ & $4,910.28$ & $5,157.82$ & $6,720.15$ \\
p1211 & 582.93 & 719.38 & $1,549.03$ & $4,104.42$ \\
p2002 & $2,116.08$ & $2,856.54$ & $5,757.24$ & $5,935.31$ \\
p3001 & 119.85 & 120.29 & $3,907.27$ & $4,523.72$ \\
p3306 & 81.51 & 142.65 & $2,194.38$ & $3,627.75$ \\
p4214 & 63.45 & $3,511.27$ & $3,711.09$ & $4,521.69$ \\
p5301 & 50.28 & 53.76 & $1,427.74$ & $3,220.31$ \\
p6107 & $2,156.04$ & $2,388.99$ & $4,618.66$ & $4,743.19$ \\
p8000 & $4,576.98$ & $7,812.28$ & $6,563.98$ & $16,754.91$ \\
\hline
\end{tabular}

\section{Discussion}

Platanus trees are widely grown as street and shade trees around cities in the world. This kind of tree includes Platanus occidentalis, Platanus orientalis, and Platanus acerifolia. Our field survey results showed that most of Platanus tree is widely planted in parks and avenues in Shanghai is $P$. orientalis. And this fielding survey results agreed with our microscopic characterization results, which the Platanus pollen collected in Shanghai was the same as $P$. orientalis pollen provided by GREER (Lenoir, NC, USA) (data not shown).

Previous study has indicated that Platanus pollen is a major contributor to pollinosis symptoms during March and April. Extensive studies on P. acerifolia allergy have been reported, however, there are few reports on allergenic protein released by $P$. orientalis trees (Pazouki et al. 2009).
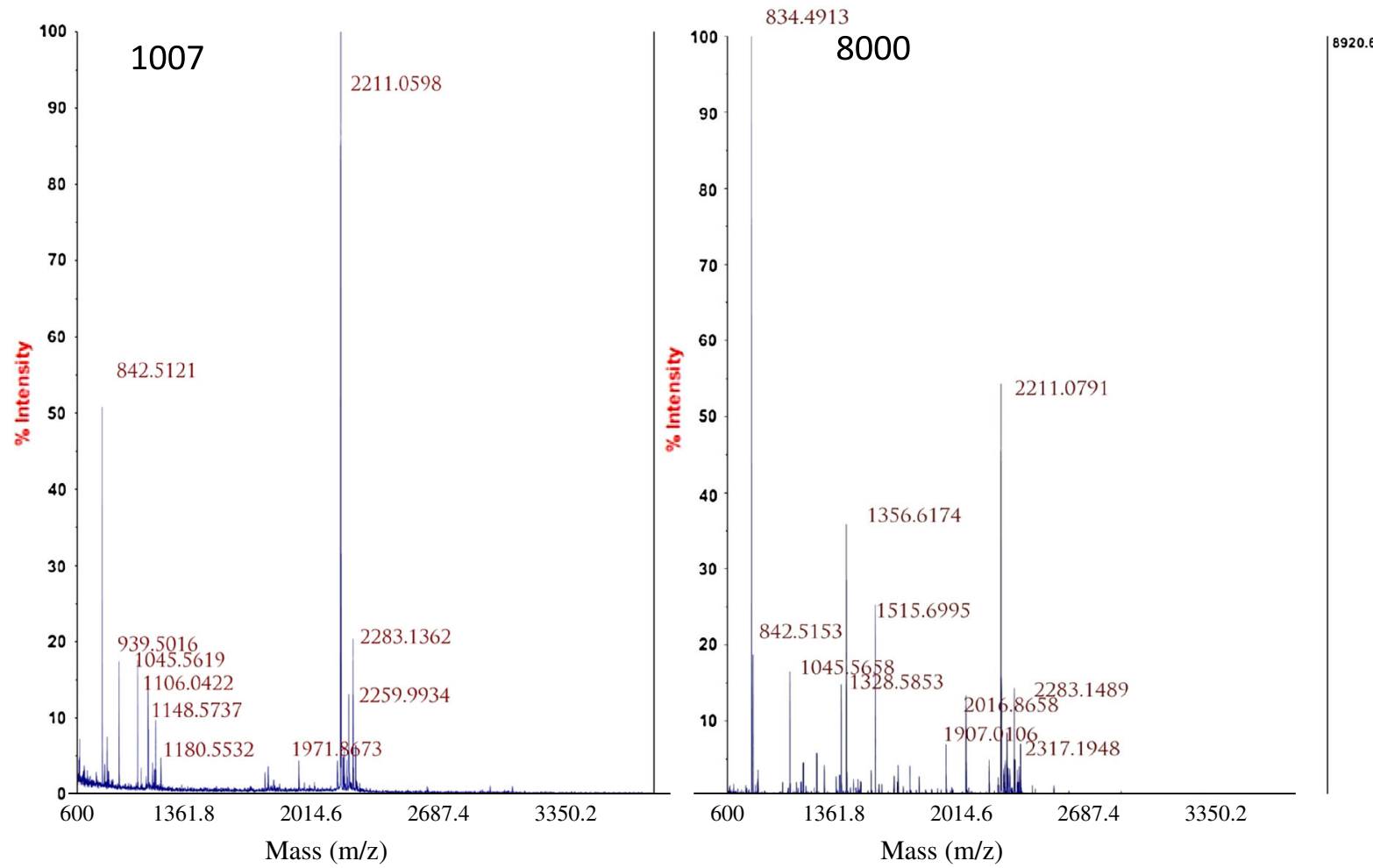

Fig. 5 TOF-MS spectra of spot 1007 and spot 8000 
Table 2 Identification of proteins expressed in Platanus orientalis pollen following exposure to gaseous pollutants

\begin{tabular}{|c|c|c|c|c|c|c|}
\hline Spot no. & Gene index & $\begin{array}{l}\text { Protein identity(TAIR } \\
\text { description) }\end{array}$ & $\mathrm{MM} / \mathrm{pI}^{\mathrm{a}}$ & $\begin{array}{l}\text { Mascot } \\
\text { score }\end{array}$ & matches & $\begin{array}{l}\text { Sequence } \\
\text { coverage }\end{array}$ \\
\hline \multirow[t]{4}{*}{1007} & gil12229949 & $\begin{array}{l}\text { RecName: Full=40S } \\
\text { ribosomal protein S12 }\end{array}$ & $15,627 / 5.35$ & 102 & $2(1)$ & 23 \\
\hline & gil195604208 & $\begin{array}{l}\text { 40S ribosomal protein } \mathrm{S} 12 \\
\text { [Zea mays] }\end{array}$ & $15,361 / 5.33$ & 71 & $1(1)$ & 12 \\
\hline & gil226505142 & $\begin{array}{l}\text { ribosomal proteinS12 } \\
\text { (homolog) [Zea mays] }\end{array}$ & $15,326 / 5.51$ & 71 & $1(1)$ & 12 \\
\hline & gil116782336 & unknown [Picea sitchensis] & $13,331 / 6.19$ & 64 & $1(1)$ & 7 \\
\hline 8000 & gil29839547 & $\begin{array}{l}\text { RecName: Full=Putative } \\
\text { invertase inhibitor; } \\
\text { AltName: Full=Pollen } \\
\text { allergen Pla a 1; AltName: } \\
\text { Allergen=Pla a } \\
\text { 1; Flags: Precursor }\end{array}$ & $19,555 / 8.89$ & 172 & $3(3)$ & 26 \\
\hline
\end{tabular}

\footnotetext{
${ }^{a}$ Molecular mass (Da) and pI of identified protein (according to the Proteinscape software; Bruker Daltonics)

b Mascot score (http://www.matrixscience.com/help/scoring_help.html)

${ }^{c}$ Sequence coverage (percentage of the complete protein sequence identified)
}

Varela et al. (1997) reported Platanus pollens (including $P$. orientalis and $P$. acerifolia) have been tested to contribute to the symptoms of patients with pollinosis. Platanus pollen in Shanghai urban atmosphere is obviously greater abundance compared with that in the suburban and rural area during its flowering season (data not shown). Importantly, main air pollutants in urban atmosphere (such as atmospheric fine particulates, sulfates, $\mathrm{SO}_{\mathrm{x}}, \mathrm{NO}_{\mathrm{x}}$ ), could be absorbed on the surface of Platanus pollen (Feng et al. 2011). These different particle types not only reflected their different sources, but would also enhance allergenicity through different mechanisms (D'Amato et al. 2007). Considering pollen allergen liberation could be affected by air pollutants (Behrendt et al. 1997; Majd et al. 2004), we hypothesized that allergenic protein expression released from Platanus pollen might be affected by air pollutants.

Our exposure experiment results showed that pollen grains become swollen and new particles could be found on the pollen surface after exposure to the mixture of gases. Chehregani et al. (2004) also demonstrated that pollen grains became folded, and airborne particles accumulate on the surface of Zinnia pollen, after grains were exposed to the polluted air of Tehran for 20 days. The morphological change of ambient pollen might affect behavior of its allergenic contents (Wang et al. 2011).
Protein released from $P$. acerifolia pollen has been studied, three allergenic $P$. acerifolia pollen proteins have been identified: one minor allergen (Pla a 3) (an aeroallergen related to food allergy) and two major allergens (Pla a 1 and Pla a 2), with molecular weights of $\sim 18$ and $\sim 44 \mathrm{kDa}$, respectively (Asturias et al. 2002, 2003; Lauer et al. 2007). Pla a1 is a nonglycosylated protein, while Pla a2 is a glycoprotein (Ibarrola et al. 2004; Fernandez-Gonzalez et al. 2010). Pla a1 represents $\sim 60 \%$ of the total IgE binding of Platanus pollen extract and can be used for specific diagnosis of Platanus (orientalis and acerifolia) pollen allergy (Asturias et al. 2003; Pazouki et al. 2009). Therefore, investigation of proteins and identification of Pla a1 released from Platanus pollen planted in Shanghai could provide fundamental data for evaluation of health risks caused by this kind of ambient allergenic pollen.

Our SDS-PAGE results demonstrated that there existed protein with molecular weights of 17-19 k Da in the Platanus pollen, and its graylevels increased after pollen exposure to air pollutants, suggesting more protein released. Varela et al. (1997) reported major protein bands of 17, 43, $45 \mathrm{kDa}$ from Platanus (acerifolia) pollen, and suggested that the $17 \mathrm{kDa}$ band was the allergenic protein. Asturias et al. (2006) claimed the presence of several allergens in Platanus (acerifolia) extracts, but only two of them, Pla a $1(18 \mathrm{kDa})$ and a $43 \mathrm{kDa}$ were allergenic protein. 
While in China, several studies focused on the identification of proteins from Platanus pollen, for example, Li et al. (2004)found 6 major protein bands with Platanus pollen (16, 22, 35, 39 and $71 \mathrm{kDa})$ and claimed that those $22-71 \mathrm{kDa}$ in size were the major allergenic proteins based on Western blot analysis. It must be pointed out that Platanus pollen was defatted with acetone $(3.44 \mathrm{~mol} / \mathrm{L})$ in the procedure of protein extracts in this study, and this chemical regent might affect the quantity and quality of allergenic content which accumulated in the intine (Suarez-Cervera et al. 1995), more studies are needed to investigate the negative effects on allergenic protein extracts in future work.

In order to testify the protein with molecular weights of 17-19 k Da in the Platanus pollen and its variety after the pollen exposure to the gaseous pollutants, two-dimensional gel electrophoresis (2DE) and mass spectrometry were employed. The 2-DE result clearly demonstrated grayscale values of 14 protein spots (Table 1) were found to increase, following our different exposure conditions, implying protein expression in Platanus pollen increase with exposure time and with $\mathrm{SO}_{2}, \mathrm{NO}_{2}, \mathrm{NH}_{3}$, and VEPs. Among the 14 protein spots, p1007 and p8000 were selected for further study by mass spectrometry (Sheoran et al. 2009). The p1007 contained 4 kinds of protein, in which none of them was allergenic and only one protein was found in the p8000 protein spot from the NCBInr database (Table 2). This protein was clearly identified as Pla a1 according to its amino acid sequence.

Behrendt et al. (1997) reported that air pollutants were one of inducers of allergen liberation, and Chehregani and Kouhkan (2008) argued that new allergenic proteins could have been found after Lilium martagon pollen exposure to diesel vehicle emissions particles (DEPs). A new protein band, with an approximate molecular weight of $26.5 \mathrm{kDa}$, also was found after Platanus pollen exposure to VEPs in this study. Therefore, our results might demonstrate that air pollutants could affect allergen liberation from Platanus pollen. Further experiments dissecting this phenomenon will be needed.

Among allergenic proteins from Platanus pollen, Pla a1 (18 kDa protein) was responsible for $79 \%$ of the Ig-E binding capacity and could be as a reliable diagnosis of Platanus (acerifolia) pollen in the allergenic reaction (Asturias et al. 2006), and was characterized using of immunoglobulin (Ig) E-immunublot analysis (Asturias et al. 2002). Based on the previous literature, the Pla a1 of $P$. orientalis pollen was regarded as a unique allergen (Asturias et al. 2003; Pazouki et al. 2009), it is reasonable to deduce that the Pla a1 protein expression increased after the $P$. orientalis pollens exposure to air pollutants, and it will contribute to pollinosis symptoms.

\section{Conclusions}

A special apparatus was designed to investigate any differences in protein expression in $P$. orientalis pollen after exposure to air pollutants, the following results were achieved: (1) after $P$. orientalis pollen exposure to the pollutant gases and particles, the pollen became swollen, and new kinds of particles could be found on the surface of the grains; (2) the results of two-dimensional gel electrophoresis and mass spectrometry analysis demonstrated that the expression of an allergenic protein $(\mathrm{Pl}$ a a1) of $P$. orientalis pollen is increased after exposure to pollutant gases and VEPs, implying that air pollutants can exacerbate the allergenicity of pollen of this genus.

Acknowledgments The research was supported by Shanghai Pujiang Talent Program, Innovation Program of Shanghai Municipal Education Commission (11Z80), the NSFC (Grant No.41273127, 41073073, 11005144), and Shanghai Leading Academic Discipline Project (No. S30109). The authors thank Professor Margaret Burchett for her the most careful revision and the two anonymous reviewers' critical but constructive suggestions.

Open Access This article is distributed under the terms of the Creative Commons Attribution License which permits any use, distribution, and reproduction in any medium, provided the original author(s) and the source are credited.

\section{References}

Asturias, J. A., Ibarrola, O., Amat, P., Tella, R., Cistero-Bahima, A., Enrique, E., et al. (2006). Purified allergens vs. complete extract in the diagnosis of plane tree pollen allergy. Clinical and Experimental Allergy, 36, 1505-1512.

Asturias, J. A., Ibarrola, I., Bartolome, B., Ojeda, I., Malet, A., \& Mart'1nez, A. (2002). Purification and characterization of Pla a1, a major allergen from Platanus acerifolia pollen. Allergy, 57, 221-227. 
Asturias, J. A., Ibarrola, I., Eraso, E., Arilla, M. C., \& Mart'inez, A. (2003). The major Platanus acerifolia pollen allergen Pla a 1 has sequence homology to invertase inhibitors. Clinical and Experimental Allergy, 33, 978-985.

Behrendt, H., Becker, W. M., Fritzsche, C., Sliwa-Tomczok, W., Tomczok, J., Friedrichs, K. H., et al. (1997). Air pollution and allergy: Experimental studies on modulation of allergen release from pollen by air pollutants. International Archives Allergy Immunology, 113, 69-74.

Bellanger, A., Bosch-cano, F., Millon, L., Ruffaldi, P., Franchi, M., \& Bernard, (2012). Reactions of airway epithelial cells to birch pollen grains previously exposed to in situ atmospheric Pb concentrations: A Preliminary assay of allergenicity. Biological Trace Element Research, 150(1-3), 391-395.

Bosch-Cano, F., Bernard, N., Sudre, B., Gillet, F., Thibaudon, M., Richard, H., et al. (2011). Human exposure to allergenic pollens: A comparison between urban and rural areas. Environmental Research, 111, 619-625.

Chehregani, A., \& Kouhkan, F. (2008). Diesel exhaust particles and allergenicity of pollen grains of Lilium martagon. Ecotoxicology and Environmental Safety, 69(3), 568-573.

Chehregani, A., Majde, A., Moin, M., Gholami, M., Shariatzadhe, M., \& Nassiri, H. (2004). Increasing allergy potency of Zinnia pollen grains in polluted areas. Ecotoxicology and Environmental Safety, 58(2), 267-272.

D’Amato, G., Cecchi, L., Bonini, S., Nunes, C., Annesi-Masesano, I., Behrendt, H., et al. (2007). Allergenic pollen and pollen allergy in Europe. Allergy, 62, 976-990.

D’Amato, G., Cecchi, L., D'Amato, M., \& Liccardi, G. (2010). Urban air pollution and climate change as environmental risk factors of respiratory allergy: An update. Journal of Investigational Allergology and Clinical Immunology, 20(2), 95-102.

Feng, M., Lu, S., Zhang, R., Shen, C., Huang, J., \& Wang, Y. (2011). Preliminary studies on complex pollution caused by ambient allergenic pollens and urban particulate matters in Shanghai. China Environment Science, 31(7), 1095-1101. (in Chinese).

Fernandez-Gonzalez, D., Gonzalez-Parrado, Z., Vega-Maray, A. M., Valencia-Barrera, R. M., Camazon-Izquierdo, B., Nuntiis, P. D., et al. (2010). Platanus pollen allergen, Pla a 1: Quantification in the atmosphere and influence on a sensitizing population. Clinical and Experimental Allergy, 40(11), 1701-1708.

Hwang, B. F., Lee, Y. L., Lin, Y. C., Jaakola, J. J., \& Guo, Y. L. (2005). Traffic related air pollution as a determinant of asthma among Taiwanese school children. Thorax, 60, 467-473.

Ibarrola, I., Arilla, M. C., Mart'ınez, A., \& Asturias, J. A. (2004). Identification of a polygalacturonase as a major allergen (Pla a 2) from Platanus acerifolia pollen. Journal of Allergy Clinical Immunology, 113, 1185-1191.

Ishizaki, T., Koizumi, K., Ikemori, R., Ishiyama, Y., \& Kushibiki, E. (1978). Studies of prevalence of Japanese cedar pollinosis among the residents in a densely cultivated area. Annals of Allergy, 58, 265-270.

Lauer, I., Miguel-Moncin, M. S., \& Abel, T. (2007). Identification of a plane pollen lipid transfer protein (Pla a 3) and its immunological relation to the peach lipid-transfer protein, Pru p 3. Clinical and Experimental Allergy, 37, 261-269.

Li, Y., Sun, X., Li, D., Liu, Y., \& Feng, X. (2004). Partial purification and analysis Platanus acerifoli of major allergenic components of wild pollen allergen. Journal of Xi'an Jiaotong University (Medical Sciences), 25(5), 481-483. (in Chinese).

Lu, S., Shao, L., Wu, M., \& Jiao, Z. (2006). Mineralogical characterization of airborne individual particulates in Beijing $\mathrm{PM}_{10}$. Journal of Environmental Sciences, 18(1), 90-95.

Lu, S., Yao, Z., Chen, X., Wu, M., Sheng, G., Fu, J., et al. (2008). The relationship between physicochemical characterization and potential toxicity of fine Particulate matter $\left(\mathrm{PM}_{2.5}\right)$ in Shanghai Atmosphere. Atmospheric Environment, 42, 7205-7214.

Lu, S., Zhang, R., Yao, Z., An, J., Zhong, Y., Wu, M., et al. (2011). Physicochemical characterization and cytotoxicity of ambient coarse, fine, and ultrafine particulate matters in Shanghai atmosphere. Atmospheric Environment, 45, 736-744.

Majd, A., Chehregani, A., Moin, M., Gholami, M., Kohno, S., Nabe, T., et al. (2004). The effects of air pollution on structures, proteins and allergenicity of pollen grains. Aerobiologia, 20(2), 111-118.

Okuyama, Y., Matsumoto, K., Okochi, H., \& Igawa, M. (2007). Adsorption of air pollutants on the grain surface of Japanese cedar pollen. Atmospheric Environment, 41(2), 253-260.

Parnia, S., Brown, J., \& Frew, A. (2002). The role of pollutants in allergic sensitization and the development of asthma. Allergy, 57, 1111-1117.

Pazouki, N., Sankian, M., Leung, P., Nejadsattari, T., KharvariNejad, R., \& Varasteh, A. (2009). Identification of cyclophilin as a novel allergen from Platanus orientalis pollens by mass spectrometry. Journal of Bioscience and Bioengineering, 107(2), 215-271.

Reid, C., \& Gamble, J. (2009). Aeroallergens, allergic disease, and climate change: Impacts and adaptation. EcoHealth, 6, 458-470.

Riediker, M., Monn, C., \& Koller, T. (2001). Air pollutants enhance rhino conjunctivitis symptoms in pollen-allergic individuals. Annal of Allergy, Asthma and Immunology, 87(4), 311-318.

Shanghai Environmental Protection Bureau (SEPB). (2012). Shanghai environmental bulletin. http://www.envir.gov. cn/law/bulletin/2012/.

Sheoran, I. S., Ross, A. R. S., Olson, D., \& Sawhney, V. K. (2009). Compatibility of plant protein extraction methods with mass spectrometry for proteome analysis. Plant Science, 176, 99-104.

Shevchenko, A., Wilm, M., Vorm, O., \& Mann, M. (1996). Mass spectrometric sequencing of proteins from silver-stained polyacrylamide gels. Analytical Chemistry, 68, 850-858.

Shi, R., \& Zhu, R. (2009). Pollinosis (pp. 74-77). China science and technology press. (in Chinese).

Suarez-Cervera, M., Marquez, J., \& Seoane-Camba, J. (1995). Pollen grain and Ubisch body development in Platanus acerifolia. Review of Palaeobotany and Palynology, 85, 63-84. 
Varela S., Subiza J., Subiza J., Rodrigez R., Garcia B., Jerz M., et al. (1997). Platanus pollen as an important cause of pollinosis. Journal of Clinical Immunology, 110(6), 748-754.

Wang, Q., Nakamura, S., Lu, S., Gong, X., Nakajima, D., Wu, D., et al. (2011). Release behavior of small sized daughter allergens from Cryptomeria japonica pollen grains during urban rainfall event. Aerobiologia, 28, 71-81.
Yamamoto, N., Nishiura, H., Honjo, T., Ishikawa, Y., \& Suzuki, K. (1995). A long-term study of atmospheric ammonia and particulate ammonium concentrations in Yokohama, Japan. Atmospheric Environment, 29(1), 97-103.

Ziska, L., Knowlton, K., Rogers, C., Dalan, D., Tierney, N., Elder, M., et al. (2011). Recent warming by latitude associated with increased length of ragweed pollen season in central North America. PNAS, 108(10), 4248-4251. 